\title{
burnr: Fire history analysis and graphics with $\mathrm{R}$
}

\author{
Steven B. Malevich ${ }^{\mathrm{a}, \mathrm{b}, *}$, Christopher H. Guiterman ${ }^{\mathrm{b}}$, Ellis Q. Margolis ${ }^{\mathrm{c}, \mathrm{b}}$ \\ ${ }^{a}$ Department of Geosciences, University of Arizona, 1040 E. 4th Street, Tucson, AZ \\ 85721, USA \\ ${ }^{b}$ Laboratory of Tree-Ring Research, University of Arizona, 1215 E. Lowell Street, \\ Tucson, AZ 85721, USA \\ ${ }^{c}$ US Geological Survey, Fort Collins Science Center, New Mexico Landscapes Field \\ Station, Santa Fe, NM 87508, USA
}

\begin{abstract}
We developed a new software package, burnr, for fire history analysis and plotting in the $\mathrm{R}$ statistical programming environment. It was developed for tree-ring fire-scar analysis, but is broadly applicable to other event analyses (e.g., avalanches, frost rings, or culturally modified trees). Our new package can read, write, and manipulate standard tree-ring fire history FHX files, produce fire-demography charts, calculate fire frequency and seasonality statistics, and run superposed epoch analysis (SEA). A key benefit of burnr is that it enables automation of analyses and plotting, especially for large data sets. The package also facilitates creative plotting, mapping, and analyses when combined with the thousands of packages available in R. In this paper, we describe the basic functionality of burnr and introduce users to fire history analyses in $\mathrm{R}$.
\end{abstract}

Keywords: Fire ecology, Statistical software, Event, Visualization, Tree ring, SEA

\footnotetext{
${ }^{*}$ Corresponding author

Email address: malevich@email.arizona.edu (Steven B. Malevich)
} 


\section{Introduction}

Faced with complicated environmental challenges such as climate change, dendrochronologists are tackling increasingly sophisticated research questions. The dendroecological fire history community has grown rapidly in recent decades, driven by the need to put increases in fire size and severity in a long-term context. Novel insights can often be gained with analyses of large tree-ring data networks (e.g. Cook, 2004) and the proliferation of publicly available data facilitates such efforts. Across the western United States, for example, researchers have built an extensive network of over 1,000 tree-ring fire history sites (Falk et al., 2011), hosted on the International Multi-Proxy Paleofire Database (IMPD). However, performing network-scale analyses is challenging without the ability to read existing data formats (e.g., FHX files) into statistical computer software, such as the popular $\mathrm{R}$ language environment (R Development Core Team, 2017). Performing fire-history research in $\mathrm{R}$ would facilitate coarse-scale, complex analyses by allowing for automated workflows, easy sharing of data and methods with collaborators or in publications, and the ability to link and analyze metadata associated with fire history data. To facilitate future growth, efficiency, and creativity in dendroecological fire history analyses, we developed burnr.

burnr is a new Open Source package for R, written for users and projects with advanced needs while being accessible for basic use. Specifically, burnr was designed to provide a variety of functions that are simple and flexible, and to bring fire history data to the rich analysis and plotting tools in the $R$ environment. Dendrochronologists are increasingly using $R$, in part due to 
the number of powerful packages that have been developed (e.g. Bunn, 2008; Altman et al., 2014; Zang and Biondi, 2015). With flexible base functionality and exposure to R, burnr can act as a foundation from which users can develop their own advanced tools for fire history, or any event-based research such as frost rings, culturally modified trees, insect outbreaks, flood scarring, or avalanche reconstructions.

The burnr package grew out of methods established by fire history studies that capitalized on the ability of tree rings to record events with annual to sub-annual precision over long time periods (e.g. Dieterich and Swetnam, 1984). Existing tree-ring fire history analysis programs, including FHX2 (Grissino-Mayer, 2001) and FHAES (Brewer et al., 2016), are widely used. We based the burnr functions on these software systems, but by facilitating analyses in $\mathrm{R}$, we hope that users will develop new research and analytical approaches.

In this paper we describe how to install burnr, and we demonstrate its basic use for manipulating and summarizing FHX files, fire - demography plotting, fire interval analysis, and superposed epoch analysis (SEA). In many of these sections we showcase some of the exciting ways that users can benefit by analyzing fire-history data in R. Each section of this paper explains code and analysis, assuming that the user has installed $R$ and loaded the burnr package (see Section 2). Text in fixed-width font indicates code that is typed or output to an interactive $\mathrm{R}$ shell. Lines prefixed with ">" denote code entered by the user. Finally, note that source code to recreate this paper's figures is available online (https://github.com/brews/burnr_2018_ manuscript_figures). Output presented in this paper is from burnr v0.2.2. 


\section{Availability and installation of burnr}

The burnr package is freely available as Open Source software through the Comprehensive R Archive Network (CRAN). R can be downloaded and installed directly from the CRAN homepage (https://cran.r-project. org/) or through an alternative R distribution. Users can install burnr from within an $\mathrm{R}$ session like any other $\mathrm{R}$ package:

> install.packages("burnr")

The library is then loaded with:

$>\operatorname{library}($ burnr)

With the package loaded, burnr functionality becomes available to the user. Development releases and source code for the project are available online (https://github.com/ltrr-arizona-edu/burnr). In addition to this paper, support documentation is distributed with the package, including an introduction (https://cran.r-project.org/web/packages/burnr/ vignettes/introduction.html).

\section{Reading, manipulating, and summarizing FHX files in $\mathrm{R}$}

With burnr, fire-history data can be read into R from FHX files. From there, $\mathrm{R}$ has the capability to edit, sort, merge, and write data back to FHX files. For example:

$>$ library (burnr) 


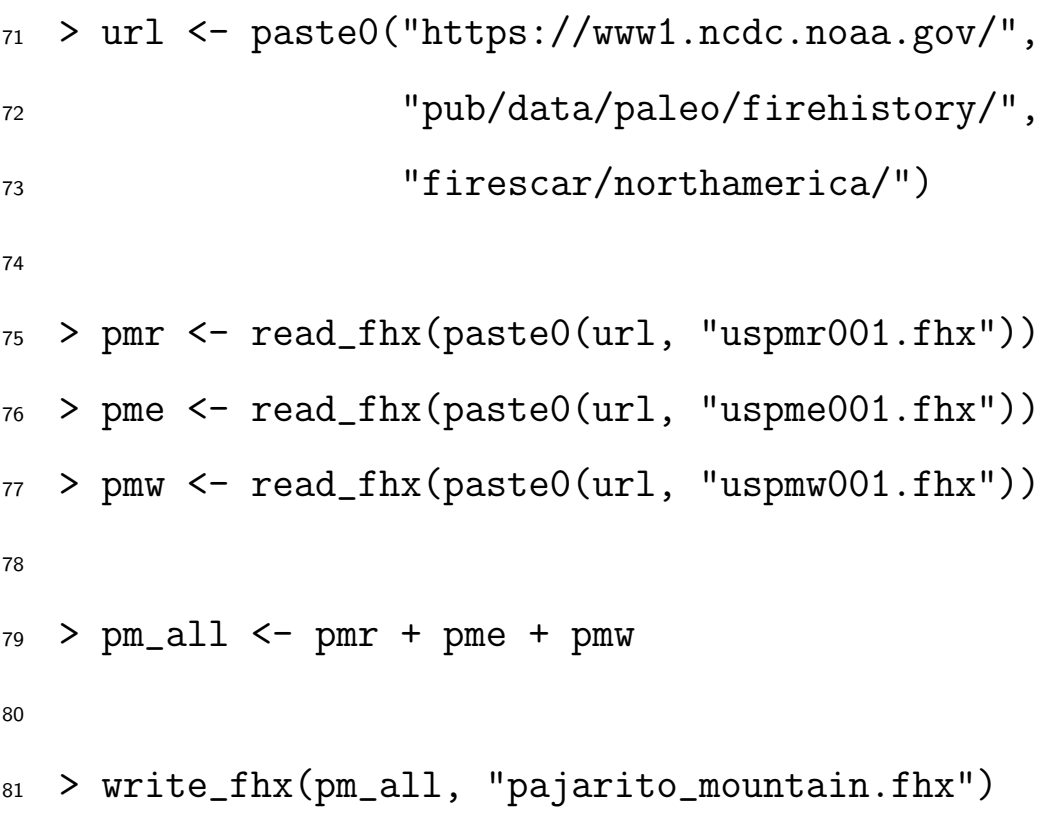

Here we are reading in three FHX files directly from URLs linking to the online IMPD file server. These data sets are assigned to variables named pmr, pme, and pmw. We then concatenate - or combine - the data with the + operator, producing a single fhx object. Concatenation also checks for duplicate series names before combining the data. The pm_all object is then written into a new FHX file in the current working directory.

Within $\mathrm{R}$, fire history data is stored as a special $\mathrm{fhx}$ object, which is similar to a simple $\mathrm{R}$ dataframe with three columns: year, series, and rec_type. The first column, year is the datum to the year in which it is recorded; series is the tree or series identifier; rec_type is the tree-derived information stored in FHX files. We found this structure to be relatively efficient for data storage and analysis in $\mathrm{R}$. The $\mathrm{fhx}$ object structure is especially effective when combined with tools utilizing a "split-apply-combine" strategy (e.g. Wickham, 2011). 
Once loaded in R, several functions are available to analyze FHX data. A quick summary of the individual series in the combined FHX files, pm_all, can be produced with:

$>$ series_stats $\left(p m \_a l l\right)$

The corresponding output from series_stats() is shown in Table 1. This gives a tree-level summary of the input data.

\begin{tabular}{lccccccccc}
\hline Series & First & Last & No. yrs & Inner & Outer & Scars & Inj. & Rec. & Interval \\
\hline PMR01 & 1664 & 1915 & 252 & pith & outer & 19 & 0 & 231 & 10.6 \\
PMR02 & 1663 & 1875 & 213 & pith & outer & 15 & 0 & 190 & 13.2 \\
PMR03 & 1676 & 1979 & 304 & inner & bark & 7 & 9 & 200 & 15.8 \\
PMR05 & 1747 & 1895 & 149 & inner & outer & 2 & 0 & 95 & 40.0 \\
PMR06 & 1653 & 1860 & 208 & pith & outer & 5 & 0 & 176 & 18.0 \\
& & & & $\vdots$ & & & & & \\
\hline
\end{tabular}

Table 1: Example series statistics, from series_stats(), for the first five trees in pm_all. The table gives the first, last, and total number of years in the series ("No. yrs"). "Inner" and "Outer" denote how each series starts and ends. Number of scars, injuries ("Inj."), and recording years ("Rec.") are given. Additionally, we give the mean fire interval ("Interval") for each series.

\section{Plotting fire history and demography}

To showcase plotting we included example fire-history data sets within the burnr package. We begin with lgr2, a fire history and demography data set from Los Griegos Peak, New Mexico that contains 11 fire-scarred or fire-injured trees and 15 non-fire-scarred trees of four species Margolis and 
107

Malevich, 2016). Below, we load the example data set to the lgr2 variable as an fhx object, as though we had read the data from an FHX file:

$>\operatorname{data}(\operatorname{lgr} 2)$

We can make a fire - demography plot of lgr2 with the basic plot function:

$>\operatorname{plot}(\operatorname{lgr} 2)$

The default plot() graphic is shown in Fig. 1. The output from the default plot function is highly customizable, but visually simple. The basic plot function includes many options, such as a customizable composite, or "rug", of fire events summarizing all fire events recorded by all series, the ability to add or remove series labels, customizable year-axis range, inclusion of tree injuries, and addition of a legend.

Colored fire - demography plots are one of the more novel features of burnr. In the example below, we add color to differentiate tree species. Tree species are drawn from metadata that can be loaded into $\mathrm{R}$ from a comma or tab-delimited file with read.csv() or read.table(). Metadata recording the species of all trees in the Los Griegos data set is included in burnr, and can be loaded with:

\section{$>\operatorname{data}\left(\operatorname{lgr} 2 \_m e t a\right)$}

This metadata can be used with the plot function because series names in the fire history lgr2 object match a column (TreeID) in the metadata. Type head(lgr2_meta) to see the first few metadata entries and get an idea of how the data set is organized. A custom fire chart that incorporates species metadata is now created with: 


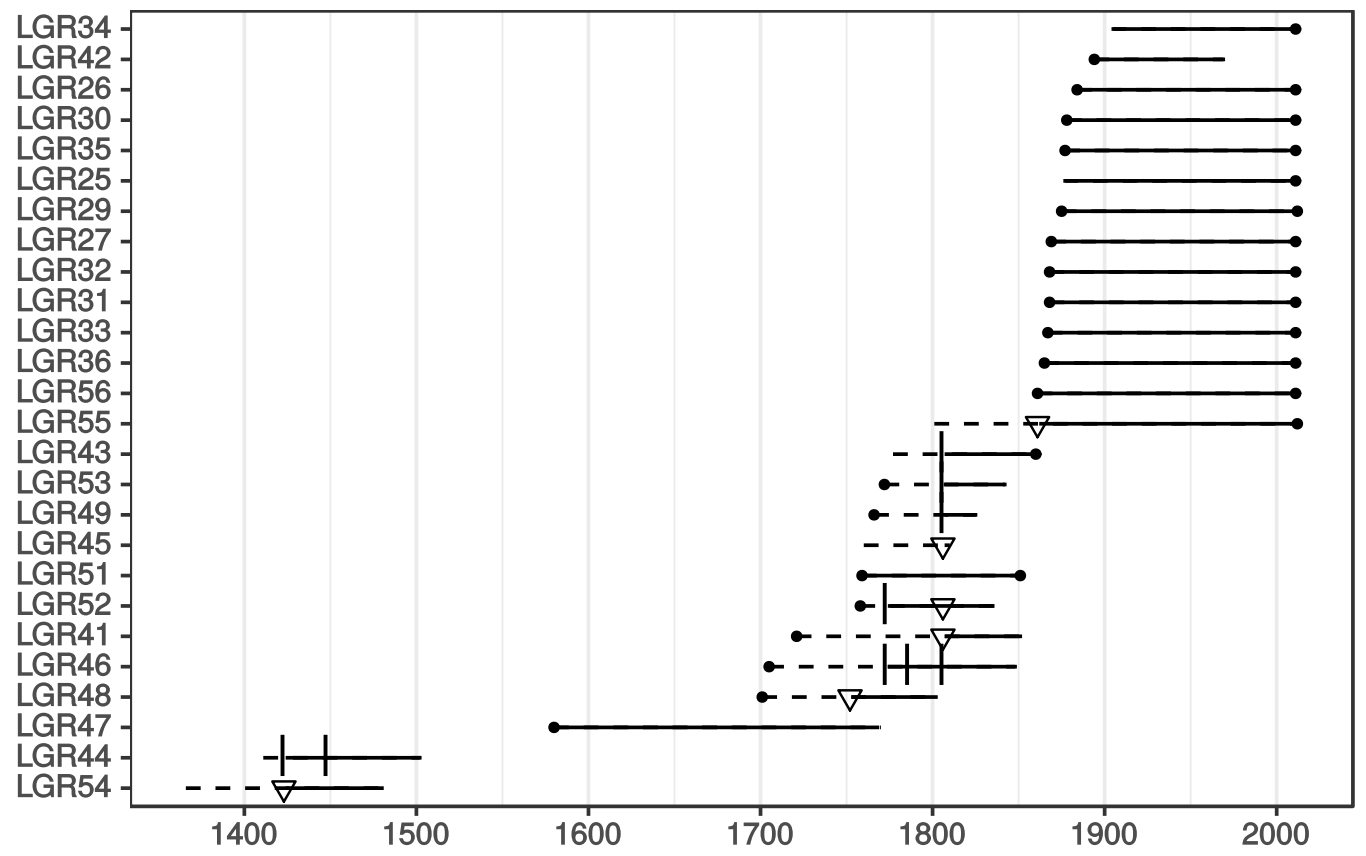

Figure 1: The default burnr fire- demography chart. Dates from pith or bark are shown with a filled circle, segments for "recording" periods are solid, and dashed segments indicate "non-recording" periods. Fire scars are indicated with a single vertical tick. Fire injuries are indicated with an empty triangle. This design emphasizes readability - a characteristic which becomes more important when plotting a larger number of records in a single graphic.

$>$ plot(lgr2,

$$
\begin{aligned}
& \text { color_group = lgr2_meta\$SpeciesID, } \\
& \text { color_id = lgr2_meta } \$ \text { TreeID, } \\
& \text { ylabels = FALSE, composite_rug = TRUE, } \\
& \text { injury_event }=\text { TRUE })
\end{aligned}
$$

The new arguments to plot() produce a fire - demography chart with colors corresponding to tree species and a fire-composite rug along the bottom of 
the graphic (Fig. 2a). The species information (color_group) is joined with lgr2 through the series names (color_id). We also remove the yaxis labels $(\mathrm{ylabels}=\mathrm{FALSE})$ to save plotting space, and add a composite rug that includes injuries with the arguments composite_rug $=$ TRUE and injury_event $=$ TRUE.

Coloring by species in fire-demography charts can be especially helpful to identify successional trends or species transitions related to fire or climate variability. For example, in Figure 2a, Pinus ponderosa (red) was present in the stand but becomes locally absent following a high-severity fire, followed by over a century of fire exclusion that promoted dominance by more mesic species: Populus tremuloides and Pseudotsuga menziesii (Margolis and Malevich, 2016). Color can be associated with other variables such as tree condition (live or dead) or age classes. It can also represent continuous variables like tree diameter at breast height or elevation.

Advanced edits of fire - demography charts requires a deeper understanding of how burnr creates graphics. Internally, burnr takes advantage of R's advanced grid plotting framework and the ggplot2 package Wickham, 2016). This helps burnr to create more sophisticated graphics (e.g., with coloring and faceting) that are also modular and customizable. To introduce this, we modify the lgr2 fire - demography chart by adding a legend - with custom placement - and a shaded polygon to highlight the species transition we described previously:

$>$ library (ggplot2)

$>\operatorname{lgr} 2_{-}$sorted <- sort(lgr2, decreasing=TRUE) 
162

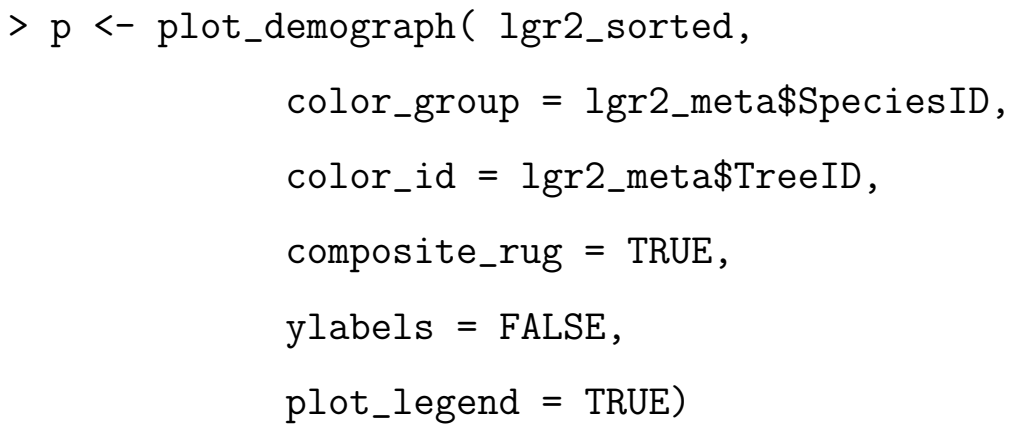

This code sets up our graphic, and assigns it to $\mathrm{p}$, but does not yet output the image. The first line imports the ggplot2 package - this is needed to modify our graphic. The next line sorts the data set by the first ring so the oldest tree series will appear along the top of the graphic. The following lines of code create a variant of our species-colored fire - demography plot from Fig. 2a. Note that we are using plot_demograph() instead of the generic plot (). plot() passes information and arguments - when used with fhx objects to plot_demograph(). We need to explicitly call plot_demograph() here because this function returns a ggplot object that we can modify to our liking. We can further customize $\mathrm{p}$ and then print $(\mathrm{p})$ to output the graphic:

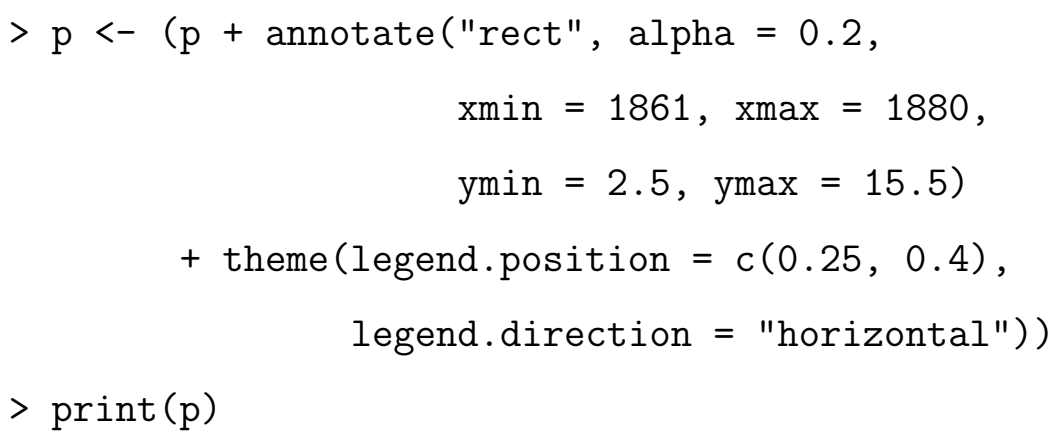

Here, we append two simple things to this plot with the + operator. First, 
with annotate(), we add a large transparent rectangle to highlight a cohort of trees regenerating after a severe fire in 1861. Next, we change the style of the plot, with theme (), by moving the legend within the plot frame, reducing white space in the graphic. The final graphic produced with these changes is shown in Fig. 2 2 . These modifications can be built upon for more radical changes to burnr graphics.

Automated multi-faceted fire - demography plots are another novel feature of burnr. Faceting separates the graphic into multiple panels, simultaneously plotting many fire history sites in one graphic, for instance. This helps visual comparisons of fire frequency or age structure across multiple sites. These figures are created with an approach nearly identical to that used for colored plots, as described previously: the plot() or plot_demograph() arguments color_group and color_id are simply replaced by the facet_group and facet_id arguments. Both faceting and coloring can be used simultaneously in the same graphic. An advanced example of this, with faceting based on spatial locations is shown in Fig. 3. This example uses different prescribed fire burn units in Bandelier National Monument, New Mexico (Fig. 3a) to group fire-scarred trees and create fire charts for each burn unit (Fig. 3b). Code to recreate this figure is available online (https: //github.com/brews/burnr_2018_manuscript_figures).

Faceting by spatial location also highlights the benefits of combining spatial and cartographic capabilities of $R$ with fire-history data in burnr. Other useful examples of mapping data from burnr include: annual fire year maps can be colored by tree-ring data type (e.g., fire scar, death date, regeneration date); annual fire year maps can be color-coded by fire scar position 
(seasonality); polygons of recent fire perimeters can be incorporated into tree-ring-derived fire year maps to make comparisons between historical and modern spatial extent of fires; Digital Elevation Models (DEM) can be integrated and points sampled at fire-scar locations to test for relationships among topographic variables and median fire intervals.

\section{Composites and fire interval analysis}

The burnr package includes tools to analyze composite summaries of fire events and fire intervals. To demonstrate this, we use a fire-history data set from Peggy Mesa (Guiterman et al., 2015). The data set (pgm) contains 41 tree series dating from 1555 to 2013, of which nine trees are fire-scarred. We create a composite of fire events recorded by $25 \%$ of scarred trees with:

$>\operatorname{data}(\mathrm{pgm})$

$>$ pgm_comp <- composite(pgm, comp_name = "PGM", filter_prop $=0.25$ )

This code loads the example pgm data set and creates a composite, assigning it to the pgm_comp variable. The comp_name argument lets us give the composite a label in the resulting $f h x$ object. By default, this composite is based on fire scars and not fire injuries. We can include injuries in the composite with the event_injuries $=$ TRUE argument to composite(). Other arguments can filter the composite series by the minimum number of trees recording, percent of trees scarred, and number of trees scarred. Because composite() returns an fhx object, we can plot it with plot (pgm_comp), or manipulate it like any other $f$ hx object. 
235 With a composite defined, we can analyze the fire intervals with:

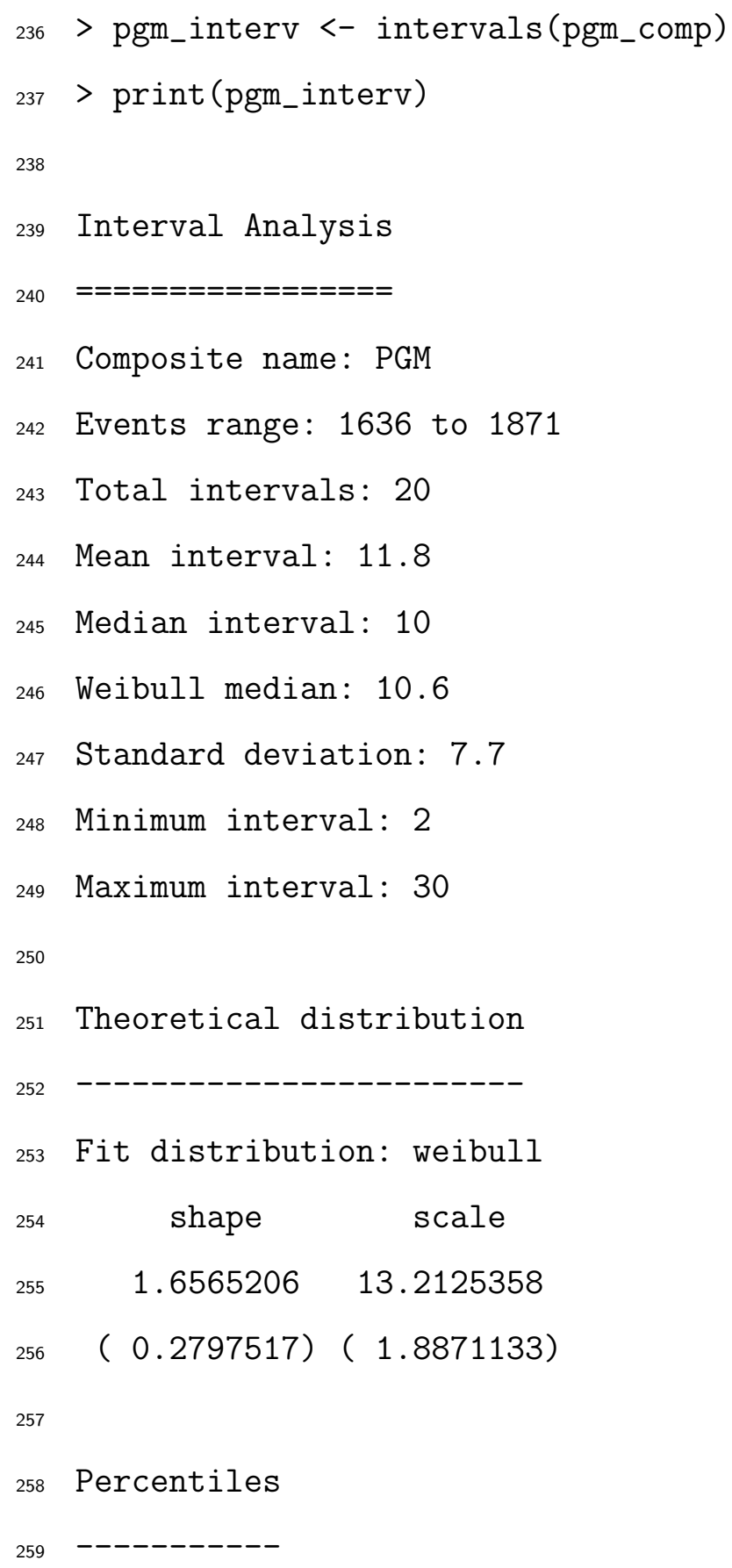




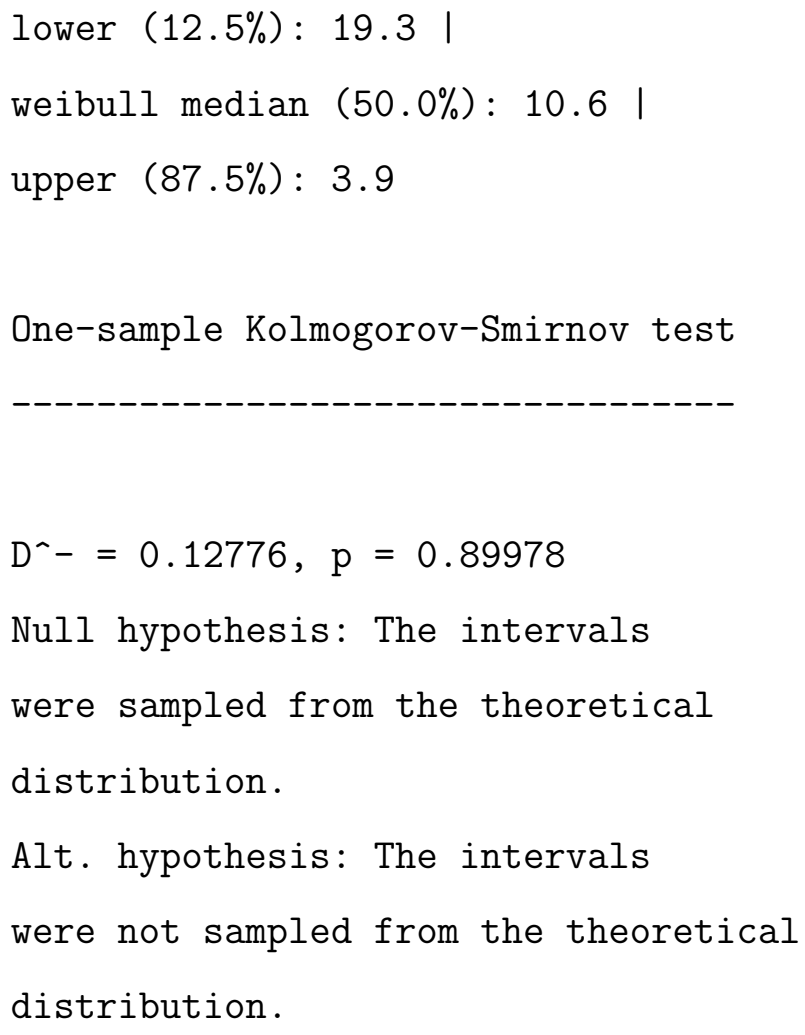

The intervals() function returns an intervals object. This object prints an analysis similar to FHX2 and FHAES interval analyses. It includes basic summary statistics, the parameters for a theoretical distribution fit to the event intervals, select percentiles of the fire intervals distribution, and the result of a Kolomogorov-Smirnov test to assess the theoretical distribution fit. By default, the intervals are fit to a Weibull distribution Grissino-Mayer, 1999), though other options are available. This is a good place to use base $\mathrm{R}$ graphics to plot the interval distribution:

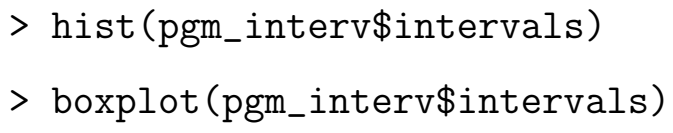


299

These functions produce a histogram and boxplot of the empirical fire intervals distribution (Fig. 4). In this case, the figure shows intervals with positive skew. Simply plotting the intervals object (e.g. plot (pgm_interv)) is also an option.

\section{Fire seasonality}

Fire seasonality is a key component of a fire regime (Agee, 1993). Seasonality of fires can have important ecological effects (e.g. Knapp et al., 2009) and is important for managers tasked with restoring fire regimes. Reconstructions of fire seasonality are based on the intra-annual position of fire scars within a tree ring (Baisan and Swetnam, 1990). The burnr package facilitates summaries of fire scar position, as well as complex analyses, such as testing for climate drivers of variability in fire seasonality (e.g. Margolis et al., 2017). Using the Peggy Mesa (pgm) data, we can get a quick summary of fire-scar positions with:

$>$ count_event_position(pgm)

(1)

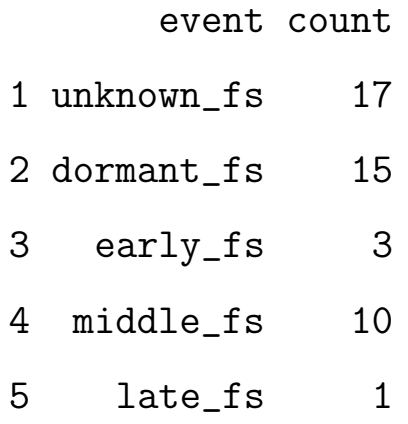

We can plot fire scar position data in a number of ways. For example, Fig. 5 is a custom graphic showing the proportion of fire scar positions 
for select years at a site, scaled by the number of trees recording fire scars annually. This was created by combining burnr functions with $R$ 's base plotting system. Plotting all fire years in charts like these can be helpful for quality control when dating and developing fire-history data sets. This graphic is also useful for visualizing changing fire seasonality through time, which may relate to human land-use changes or the influence of climate variability - such as North American monsoon failure (e.g. Margolis et al. 2017). The code to recreate this figure is available online (https://github. com/brews/burnr_2018_manuscript_figures).

\section{Superposed Epoch Analysis}

Fire-climate relationships are fundamental to projecting future fire risk (Westerling, 2006; Moritz et al., 2012; Littell et al., 2016). Fire-climate relationships can be quantified in burnr using superposed epoch analysis (SEA; Swetnam, 1993). SEA is a compositing tool that tests for inter-annual climate-fire relationships by calculating the departure of a climate time series from average conditions for each year and then using non-parametric bootstrapping to estimate the significance of the departure. Several programs and software packages implement SEA, including but not limited to FHX2 (Grissino-Mayer, 2001), dplR (Bunn, 2008), and FHAES (Brewer et al., 2016). The output of sea() in burnr is similar to the EVENT program (Holmes and Swetnam, 1994) as implemented in FHX2. SEA is an area of continuing development in burnr as we add new methods for handling time series data (e.g. Adams et al., 2003).

To demonstrate the basic functionality of SEA in burnr, we use the Peggy 
338

340

342

Mesa fire composites, described previously, and an example tree-ring reconstructed climate time series of summer Palmer Drought Severity Index (PDSI) nearest to Peggy Mesa (Cook and Krusic, 2004, from gridpoint 133).

This PSDI time series is included with burnr.

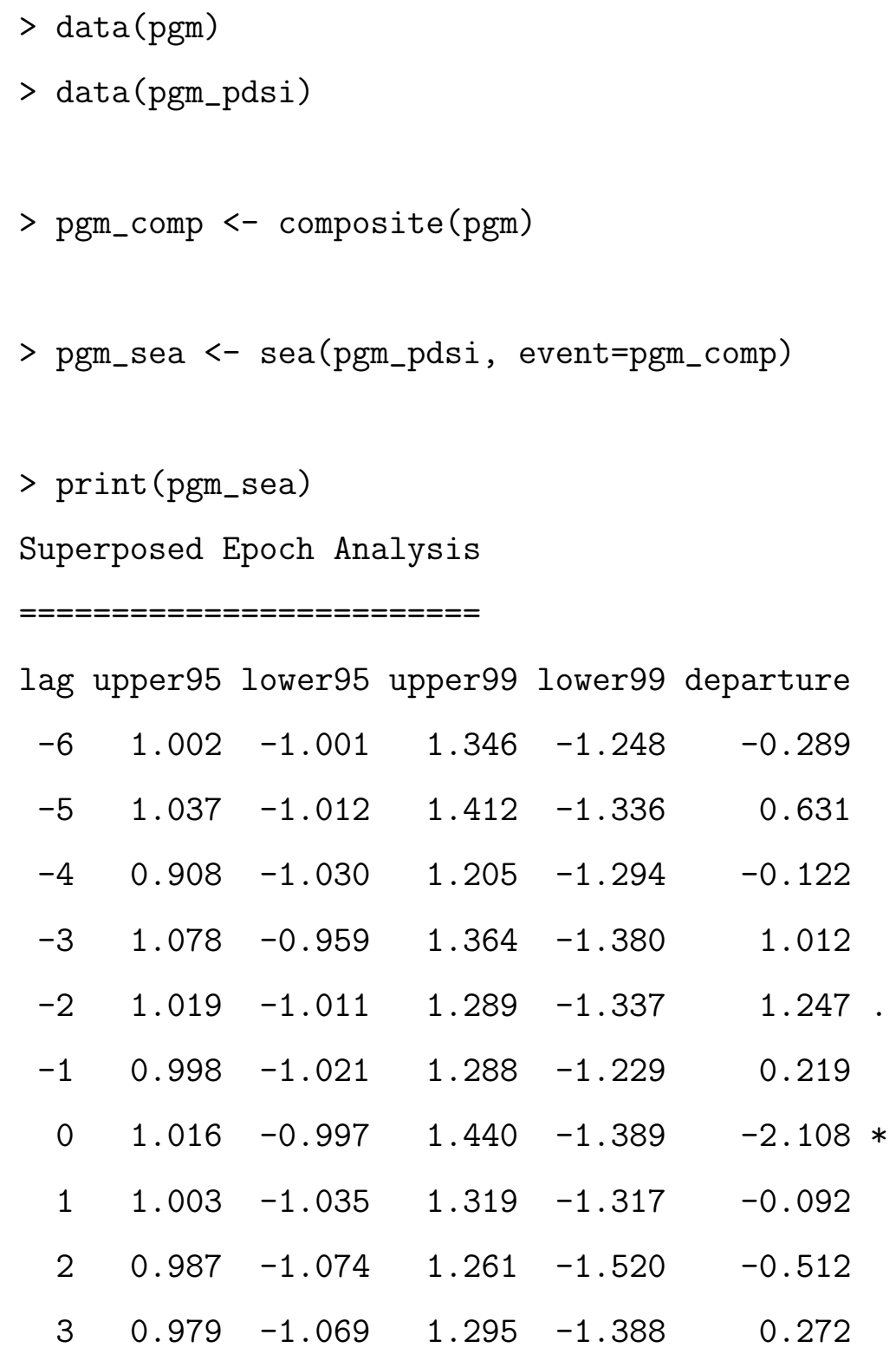


$\begin{array}{llllll}4 & 1.006 & -0.988 & 1.307 & -1.301 & 0.278\end{array}$

Signif. codes: 0.01 '*' 0.05 '.'

After loading the example data set and creating the composite, the function sea() returns a sea object that we assign to pgm_sea. By default, this SEA is conducted with 1,000 bootstrap iterations, though this can be specified with the $\mathrm{n}_{-}$iter argument to sea(). By default, the SEA includes four lag years following and six lag years prior to the key event year, or the year of fire identified in the PGM composite, in this case. Printing a sea object produces a brief summary table giving upper and lower confidence intervals for the lagged years around fire events in the PGM composite. Note that the right-most columns denote the departure of the climate time series from its mean, and significance of this departure, based on the bootstrapped intervals. Finally, we can plot the sea object with the generic plot() function, producing a simple bar plot with confidence intervals (figure not included).

\section{Conclusion}

The new burnr package for $\mathrm{R}$ is a powerful and flexible set of tools designed to meet the demands of modern fire history and event-based research. This paper introduces burnr's ability to explore, summarize, and visualize tree-ring fire and demography data, analyze fire return intervals, visualize and quantify fire seasonality, and test for fire-climate relationships. We present 
a few examples of how burnr graphics and analyses can be expanded and tailored for complex data sets and research questions, including spatial analyses. A major advancement of burnr is to bring fire history data into the $\mathrm{R}$ computing environment, facilitating innovation and automation of large data analysis. The package has been used on multiple data sets containing more than 1,000 fire scarred trees and more than 8,000 fire scars (e.g. Margolis et al. 2017). Other non-fire event research may also benefit from burnr. The burnr package provides researchers with an Open Source tool that enables flexibility and transparency. It is our hope that burnr will promote collaboration and inspire creative and sophisticated research projects that advance the fire history field.

\section{Acknowledgements}

Development of burnr was initiated with support from the Central Oregon Fire Management Service (Deschutes and Ochoco National Forests, Crooked River National Grassland, and Prineville District Bureau of Land Management), Emily Heyerdahl (US Forest Service) and Don Falk (University of Arizona). The authors were supported by an EPA STAR Fellowship (to C.H.G.) and by the U.S. Geological Survey Western Mountains Initiative. Comments and discussion with T.W. Swetnam, C.H. Baisan, C.D. Allen, L.B. Johnson, and P. Brewer improved burnr. We thank the many early users and beta testers that helped us to develop and refine this software. This manuscript benefited from the thoughtful feedback of L. D. Daniels, L. B. Johnson, J. Powell and an anonymous reviewer. Background map tiles in Figure $3 \mathrm{a}$ are available from Stamen Design (http://stamen.com) under a 
Creative Commons Attribution 3.0 license. Any use of trade, firm, or product names is for descriptive purposes only and does not imply endorsement by the U.S. Government.

Adams, J. B., Mann, M. E., Ammann, C. M., 2003. Proxy evidence for an El Nino-like response to volcanic forcing. Nature; London 426 (6964), 274-8.

Agee, J. K., 1993. Fire ecology of Pacific Northwest forests. Island Press, Washington, D.C.

Altman, J., Fibich, P., Dolezal, J., Aakala, T., 2014. TRADER: A package for Tree Ring Analysis of Disturbance Events in R. Dendrochronologia $32(2), 107-112$.

Baisan, C. H., Swetnam, T. W., 1990. Fire history on a desert mountain range: Rincon Mountain Wilderness, Arizona, U.S.A. Canadian Journal of Forest Research 20 (10), 1559-1569.

Brewer, P. W., Velsquez, M. E., Sutherland, E. K., Falk, D. A., 2016. Fire History Analysis and Exploration System - FHAES v2.0.1.

URL https://doi.org/10.5281/zenodo.48446

Bunn, A. G., 2008. A dendrochronology program library in R (dplR). Dendrochronologia 26 (2), 115-124.

Cook, E. R., 2004. Long-Term Aridity Changes in the Western United States. Science 306 (5698), 1015-1018.

Cook, E. R., Krusic, P. J., 2004. The North American Drought Atlas. 
URL http://iridl.ldeo.columbia.edu/SOURCES/.LDEO/.TRL/ . NADA2004/.pdsi-atlas.html

Dieterich, J. H., Swetnam, T. W., 1984. Dendrochronology of a fire-scarred ponderosa pine. Forest Sci. 30 (1), 238-247.

Falk, D. A., Heyerdahl, E. K., Brown, P. M., Farris, C., Fule, P. Z., McKenzie, D., Swetnam, T. W., Taylor, A. H., Van Horne, M. L., 2011. Multiscale controls of historical forest-fire regimes: new insights from fire-scar networks. Frontiers in Ecology and the Environment 9 (8), 446-454.

Grissino-Mayer, H. D., 1999. Modeling fire interval data from the American southwest with the Weibull distribution. Int. J. Wildland Fire 9 (1), 37-50.

Grissino-Mayer, H. D., 2001. FHX2 - Software for Analyzing Temporal and Spatial Patterns in Fire Regimes from Tree Rings. Tree-Ring Research 51 (1), 115-124.

Guiterman, C. H., Margolis, E. Q., Swetnam, T. W., 2015. Dendroecological Methods For Reconstructing High-Severity Fire In Pine-Oak Forests. TreeRing Research 71 (2), 67-77.

Knapp, E. E., Estes, B. L., Skinner, C. N., 2009. Ecological effects of prescribed fire season: a literature review and synthesis for managers. General Technical Report PSW-GTR-224, U.S. Department of Agriculture, Albany, California.

Littell, J. S., Peterson, D. L., Riley, K. L., Liu, Y., Luce, C. H., 2016. A review of the relationships between drought and forest fire in the United States. Global Change Biology 22 (7), 2353-2369. 
Margolis, E. Q., Malevich, S. B., 2016. Historical dominance of low-severity fire in dry and wet mixed-conifer forest habitats of the endangered terrestrial Jemez Mountains salamander (Plethodon neomexicanus). Forest Ecology and Management 375, 12-26.

Margolis, E. Q., Woodhouse, C. A., Swetnam, T. W., 2017. Drought, multiseasonal climate, and wildfire in northern New Mexico. Climatic Change $142(3-4), 433-446$.

Moritz, M. A., Parisien, M.-A., Batllori, E., Krawchuk, M. A., Van Dorn, J., Ganz, D. J., Hayhoe, K., 2012. Climate change and disruptions to global fire activity. Ecosphere 3 (6).

R Development Core Team, 2017. R: A language and environment for statistical computing.

URL http://www.R-project.org

Swetnam, T. W., 1993. Fire History and Climate Change in Giant Sequoia Groves. Science 262 (5135), 885-889.

Westerling, A. L., 2006. Warming and Earlier Spring Increase Western U.S. Forest Wildfire Activity. Science 313 (5789), 940-943.

Wickham, H., 2011. The Split-Apply-Combine Strategy for Data Analysis. Journal of Statistical Software 40 (1).

Wickham, H., 2016. ggplot2: elegant graphics for data analysis, second edition Edition. Use R! Springer. 
470 Zang, C., Biondi, F., 2015. treeclim: an R package for the numerical calibra471 tion of proxy-climate relationships. Ecography 38 (4), 431-436. 
a)

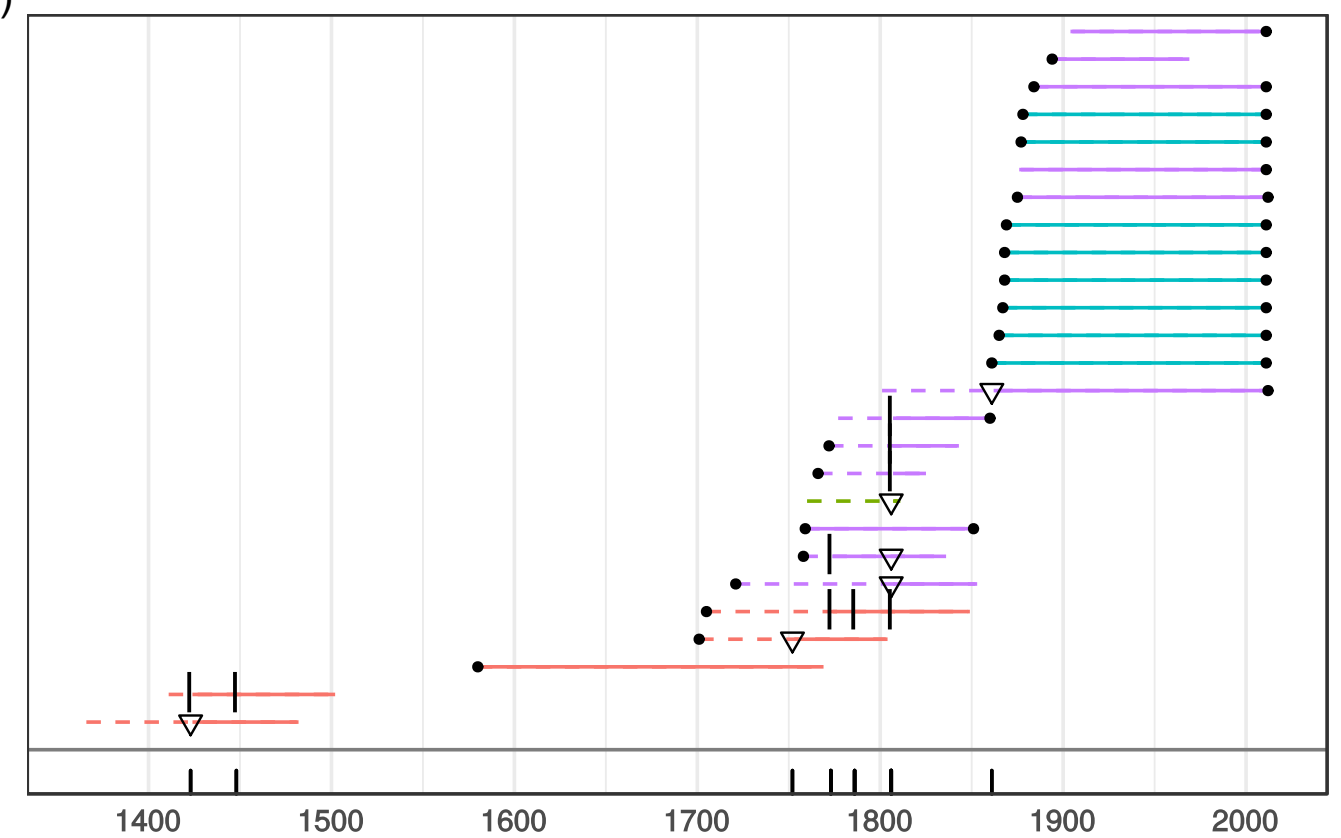

b)

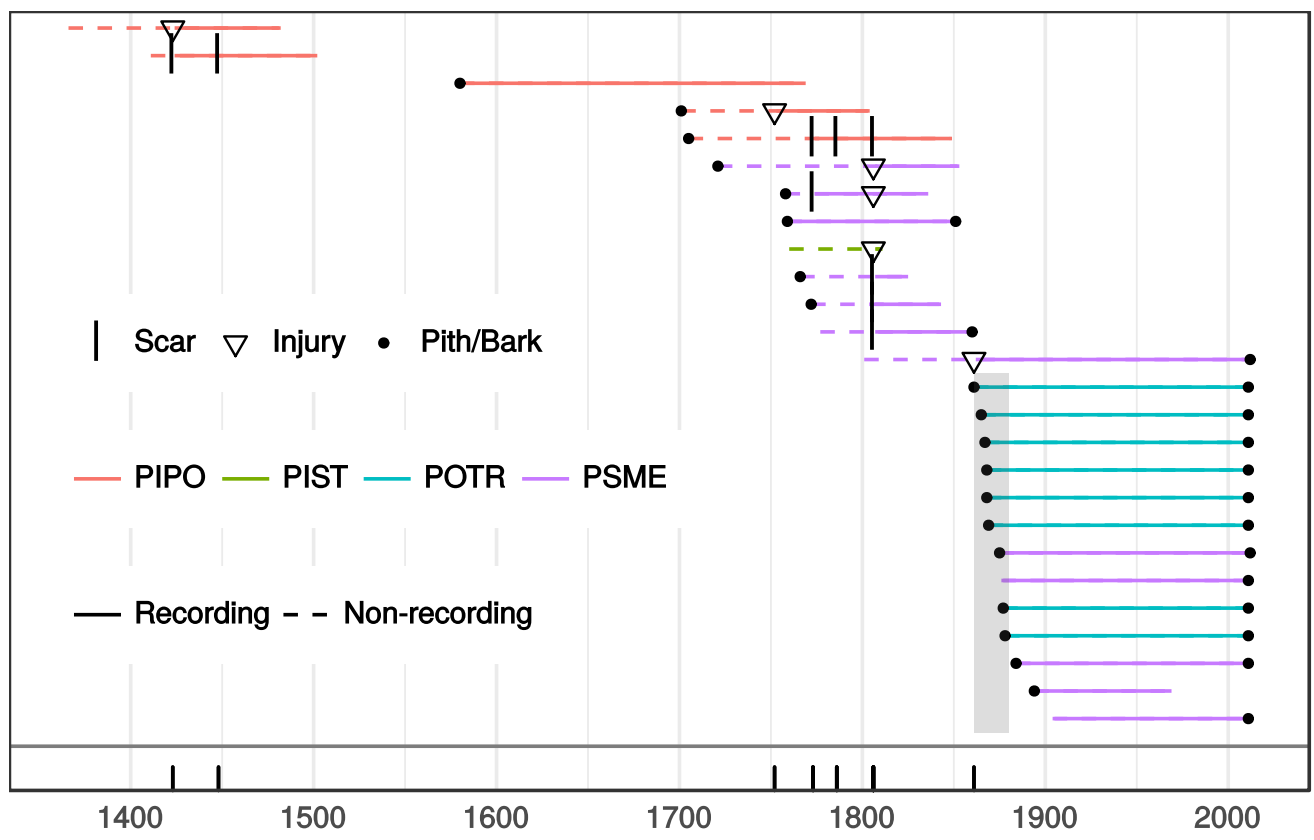

Figure 2: Custom fire - demography chart with species coloring and simple composite fire record (a). Adding legend and annotation to highlight a post-fire cohort (b). 
a)

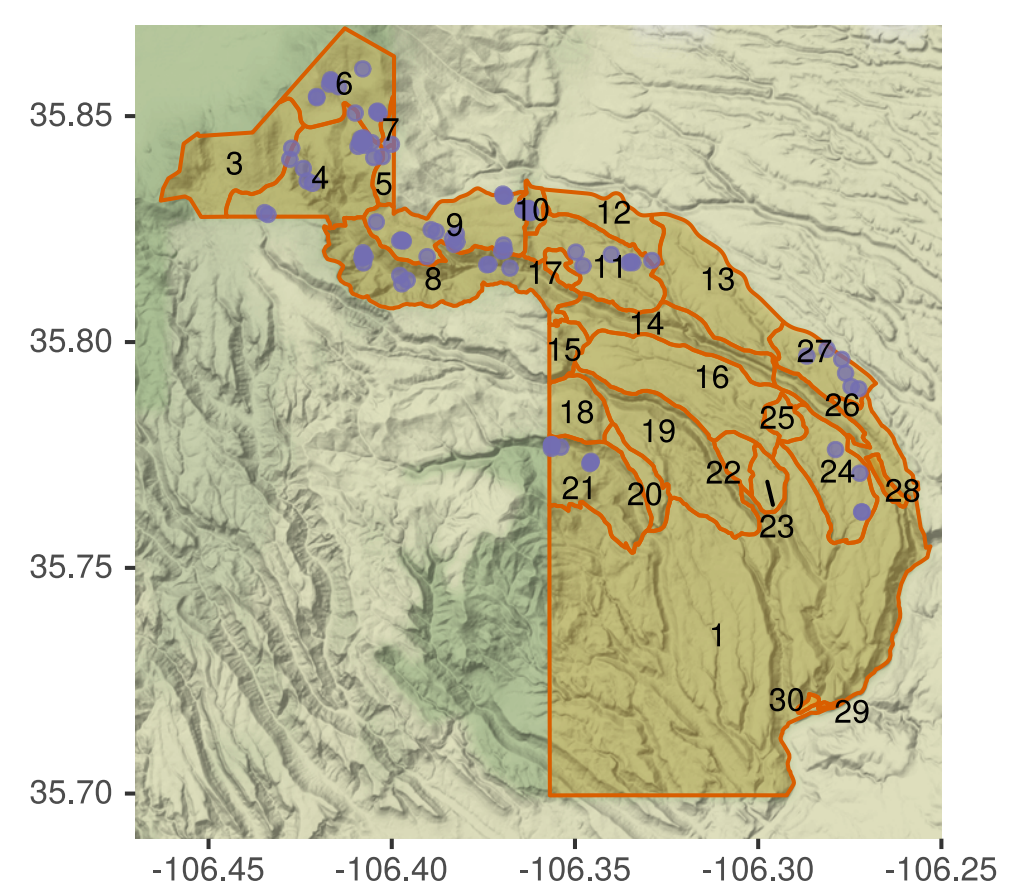

b)
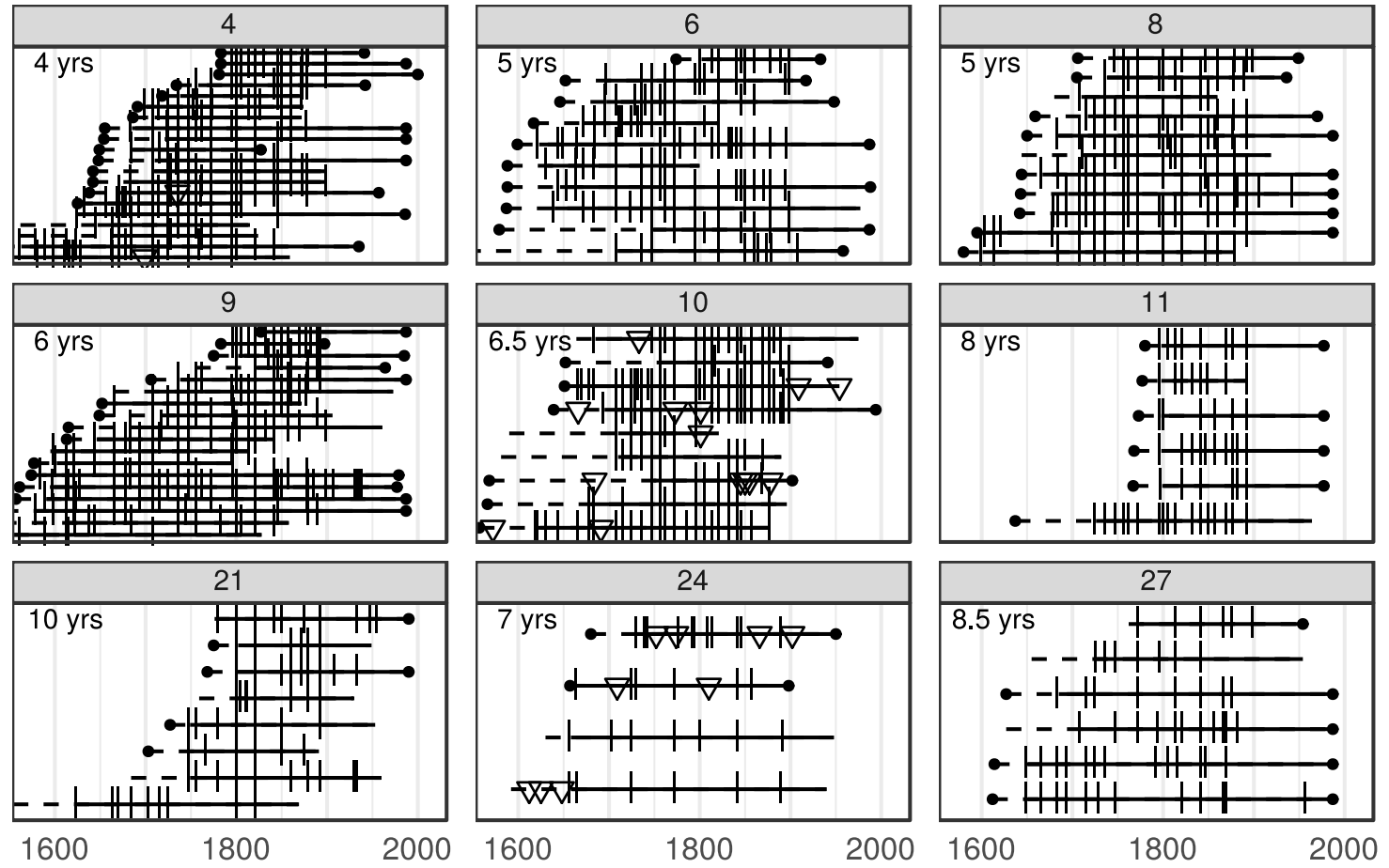

Figure 3: Map of sampled fire-scarred tree $35($ dots) and prescribed fire units (numbered polygons) in Bandelier National Monument, New Mexico (a). Faceted fire chart of the nine fire units with the most samples (b). Facet titles correspond to burn units in the map. Annotations within each facet note median fire interval. 

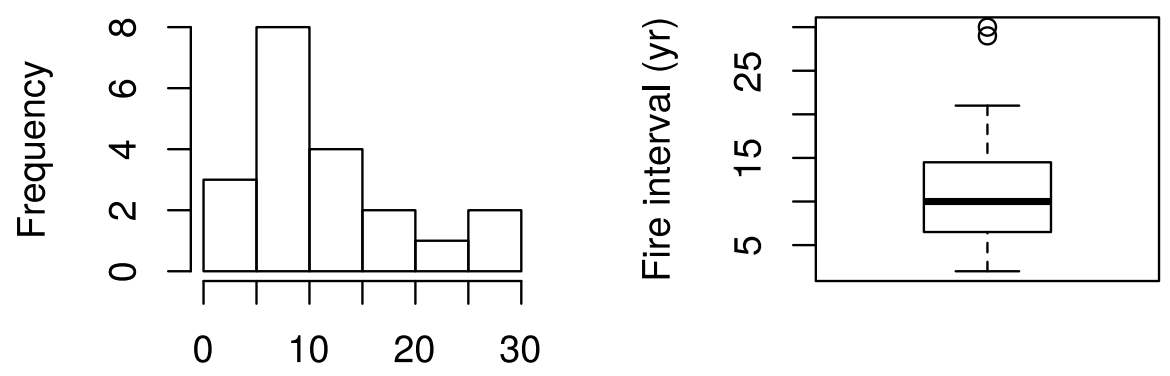

Fire interval (yr)

Figure 4: Histogram and boxplot of the composite fire intervals for Peggy Mesa, New Mexico. 

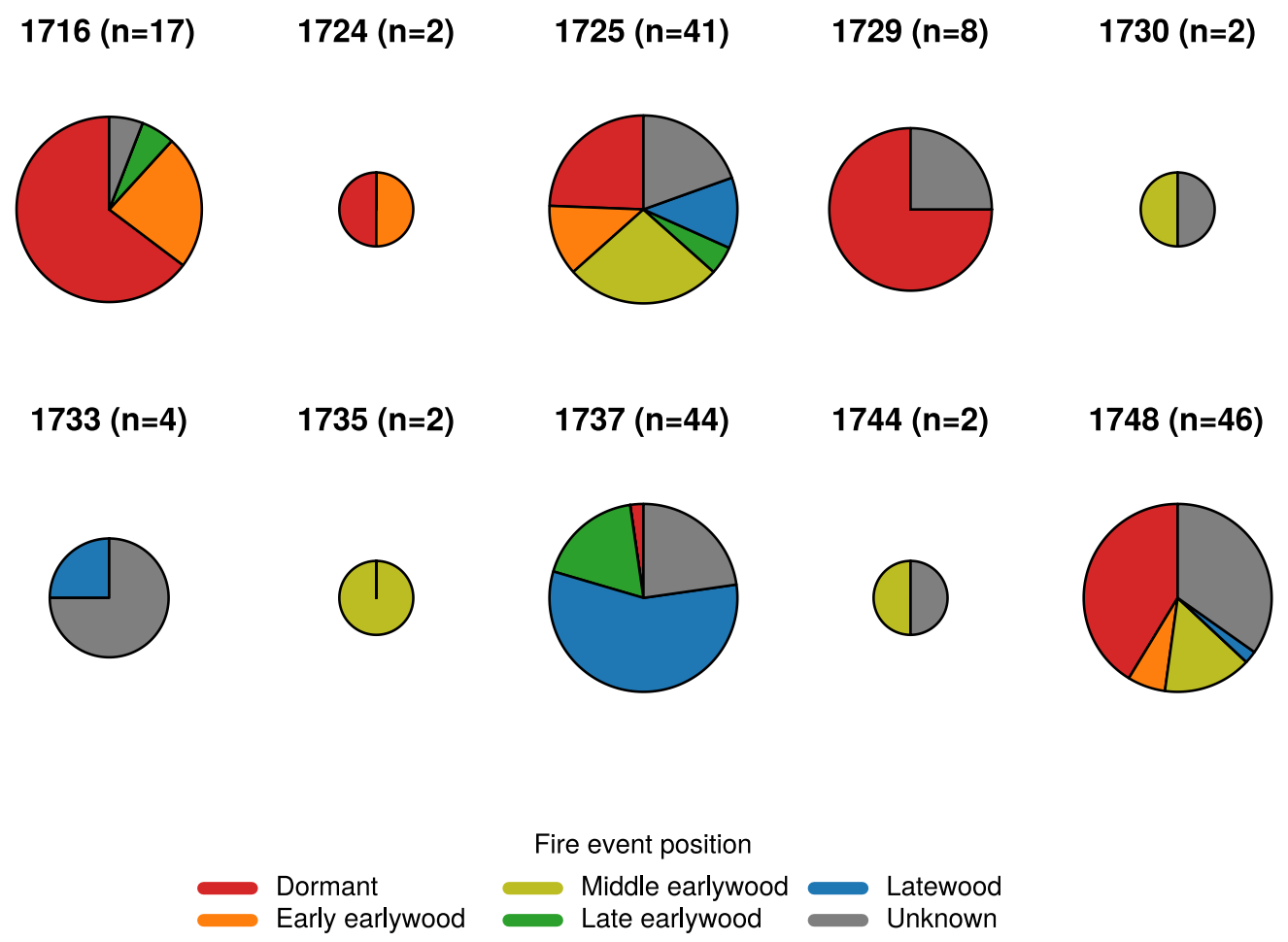

Figure 5: Pie charts indicating seasonality of fire events for fire years in Bandelier National Monument $(1716-1748)$. The size of the circle is proportional to the number of trees recording fire in that year $(n)$, with pie slices indicating the intra-ring position of those scars. 